\title{
Development and Calibration of Pendulum Type Test Rig
}

\author{
K. Prasanthkumar* and M. Saravanakumar \\ Department of Farm Machinery and Bio Energy, AEC \& RI, TNAU, \\ Kumulur, Trichy, T.N., India \\ *Corresponding author
}

\section{A B S T R A C T}

\section{Keywords}

Pendulum type test rig, Cutting energy, Calibration, Swing arm, Linear and impact cutting.

Article Info

\section{Accepted:}

19 July 2017

Available Online:

10 September 2017
Cutting of agricultural crops or biological material is primarily done by shearing and impact. Impact cutting was proven to be more suitable for cutting various. The necessity to determine the physico-mechanical property such as energy requirement for cutting stalks important to design a cutter. The pendulum type test rig was found to be useful for measuring the impact cutting energy. So the pendulum type test rig was developed and calibrated. A linear relationship between the angle of release and reach with high co-efficient of determination $\left(\mathrm{R}^{2}\right)$ for all the three weights was observed.

\section{Introduction}

Cutting of stalks is an important process involved in cassava sett cutting, sorghum harvesting, forage harvesting, cutting weed, stalk shredding and lawn mowing. The impact type rotary cutters were used in cutting operations due to its simplicity in construction, low maintenance cost and ability to cut both small and large diameter stalks (McRandal and McNulty, 1978).

Visvanathan et al., (1996) used a pendulum impact shear test apparatus to measure the energy required to cut cassava tubers and the apparatus consisted of cutting knife at the end of pendulum arm and a spring loaded lock to release the arm from various heights. Hoseinzadeh et al., (2009) constructed a pendulum impact testing apparatus for measuring the shearing energy of three wheat varieties and the pendulum test rig consisted of a single sickle knife section, trapezoidal shape with $76 \mathrm{~mm}$ base length and $55 \mathrm{~mm}$ height, heavy anvil with minimum vibration, a wooden metallic pendulum and a support for stem fixing.

Alizadeh et al., (2011) fabricated and calibrated a pendulum impact testing apparatus for measuring the cutting energy of different rice varieties and they concluded that the angle of release and reach were in linear relationship with high co-efficient of determination. Hemmatian et al., (2012) developed the impact type pendulum for measuring the shearing energy of sugarcane stems by which energy and knife velocity in 
its lowest position quantities were obtained using the theoretical equations. Dange et al., (2012) constructed a pendulum test rig to measure the cutting energy of pigeon pea stems and it has a fixed hand vice for holding the stems, the bench vice could be moved at right angle to the plane of the pendulum swing in order to vary the height of cut. Azadbakht et al., (2014) constructed and calibrated a pendulum system based on the principle of conservation of energy and they concluded that the angle of release and reach were in linear relationship.

\section{Materials and Methods}

In order to measure the cutting energy of stems, a pendulum type test rig was developed and calibrated. The pendulum type test rig works under the principle of law of conservation of energy. In this test rig the potential energy was transformed to kinetic energy.

\section{Fabrication of pendulum type test rig}

Based on the inferences of researchers (Prasad and Gupta, 1975; Visvanathan et al., 1996; Yilgep and Mohammad, 2005; Reza, 2007; Koloor and Kiani, 2007; Mahmoodi and Jafari, 2010; Dange et al., 2012; Hemmatian et al., 2012; Azadbakht et al., 2014) the pendulum type test rig was developed with the following major components main frame, swing arm, bench vice for holding stalk (Stalk holder) and angle indicator as detailed below.

\section{Main frame}

Two trapezoidal frames were fabricated using L-angles for main frame. Lateral supports were provided on both the trapezoidal frame using flats to arrest the lateral movement of the main frame. Two pillow block bearings were mounted on the top of the trapezoidal frame with bolt nut to hold the rotating shaft of the swing arm (Fig. 1).

\section{Swing arm}

The main part of the pendulum type test rig is swing arm. The swing arm was made using two mild steel rectangular tubes. Commercially available plain shaft was used as rotating shaft. The rotating shaft along with the swing arm is fixed on the trapezoidal frame through pillow block bearing. A weight holder was attached on one side of the swing arm at $1020 \mathrm{~mm}$ from the top. This provision was made to add additional weight if required. On the other side of the swing arm a blade mounting platform was attached at the bottom. Provisions were made on the blade mounting platform to vary the approach angle of blade from 0 to $30^{\circ}$ (Fig. 2).

\section{Stalk holder}

A commercially available bench vice was used for holding the stalk for cut. The bench wise was bolted to the bed provided in the stalk holder (Fig. 3).

\section{Angle indicator}

A commercially available protractor with angular divisions was used as angular indicator for measuring the angular displacement. The protractor was graduated with a least count of $0.5^{\circ}$. Two needles were fixed on the rotating shaft such that one needle called angle indicator needle is free to stay at the maximum angular displacement (non-return type) and other called swing arm needle moves with rotating shaft and swing arm (Fig. 3).

\section{Calibration of pendulum type test rig}

The pendulum type test rig was calibrated with different weights and different angle of 
release of the swing arm. First, the swing arm was released from one side with an angular displacement of $5^{\circ}(\theta)$ and allowed to swing to other side freely to make an angular displacement (angle of reach) of $\theta_{0}$. This procedure was repeated upto an angular displacement of $90^{\circ}$ with an increment of $5^{\circ}$ and their respective angle of reach on the other side was noted as ' $\theta_{0}$ ' and plotted on the graph between angle of release and reach to analyze the relationship. The pendulum type test rig was first calibrated for swing arm own weight, then $1 \mathrm{~kg}$ and $2 \mathrm{~kg}$ weights were added to the swing arm (Fig. 3).

\section{Results and Discussion}

The measured values of angle of reach are presented in table 1 . The results obtained on the relationship between the angle of release $(\theta)$ and angle of reach $\left(\theta_{0}\right)$ of the swing arm without stem is presented in figure 4. A linear relationship between the angle of release $(\theta)$ and reach $\left(\theta_{0}\right)$ with high co-efficient of determination $\left(\mathrm{R}^{2}\right)$ for all the three weights was observed. There was a minimum loss of cutting energy for all the experiments, this might be due to the friction between the movable parts and air resistance.

Table.1 Calibration of pendulum type test rig

\begin{tabular}{|c|c|c|c|c|}
\hline \multirow[b]{2}{*}{ S. No } & \multirow[b]{2}{*}{$\begin{array}{c}\text { Angle of release, } \\
\qquad \theta\left(^{\circ}\right)\end{array}$} & \multicolumn{3}{|c|}{ Angle of reach, $\theta_{0}\left(^{\circ}\right)$} \\
\hline & & $\begin{array}{c}\text { Swing arm without } \\
\text { weight }\end{array}$ & $\begin{array}{c}\text { Swing arm with } 1 \text { kg } \\
\text { weight }\end{array}$ & $\begin{array}{c}\text { Swing arm with } 2 \text { kg } \\
\text { weight }\end{array}$ \\
\hline 1 & 5 & 3 & 3.5 & 4.0 \\
\hline 2 & 10 & 8 & 8.5 & 9.0 \\
\hline 3 & 15 & 13 & 13.5 & 14.0 \\
\hline 4 & 20 & 18 & 18.5 & 19.0 \\
\hline 5 & 25 & 23 & 23.5 & 24.0 \\
\hline 6 & 30 & 27 & 28.5 & 29.0 \\
\hline 7 & 35 & 32 & 33.5 & 34.0 \\
\hline 8 & 40 & 37 & 38.0 & 38.5 \\
\hline 9 & 45 & 42 & 42.5 & 43.0 \\
\hline 10 & 50 & 47 & 47.5 & 48.5 \\
\hline 11 & 55 & 51 & 52.0 & 53.0 \\
\hline 12 & 60 & 56 & 57.0 & 58.0 \\
\hline 13 & 65 & 61 & 62.0 & 63.0 \\
\hline 14 & 70 & 66 & 66.0 & 68.0 \\
\hline 15 & 75 & 71 & 71.0 & 72.0 \\
\hline 16 & 80 & 76 & 75.0 & 76.0 \\
\hline 17 & 85 & 80 & 80.0 & 80.5 \\
\hline 18 & 90 & 84 & 84.0 & 84.0 \\
\hline
\end{tabular}




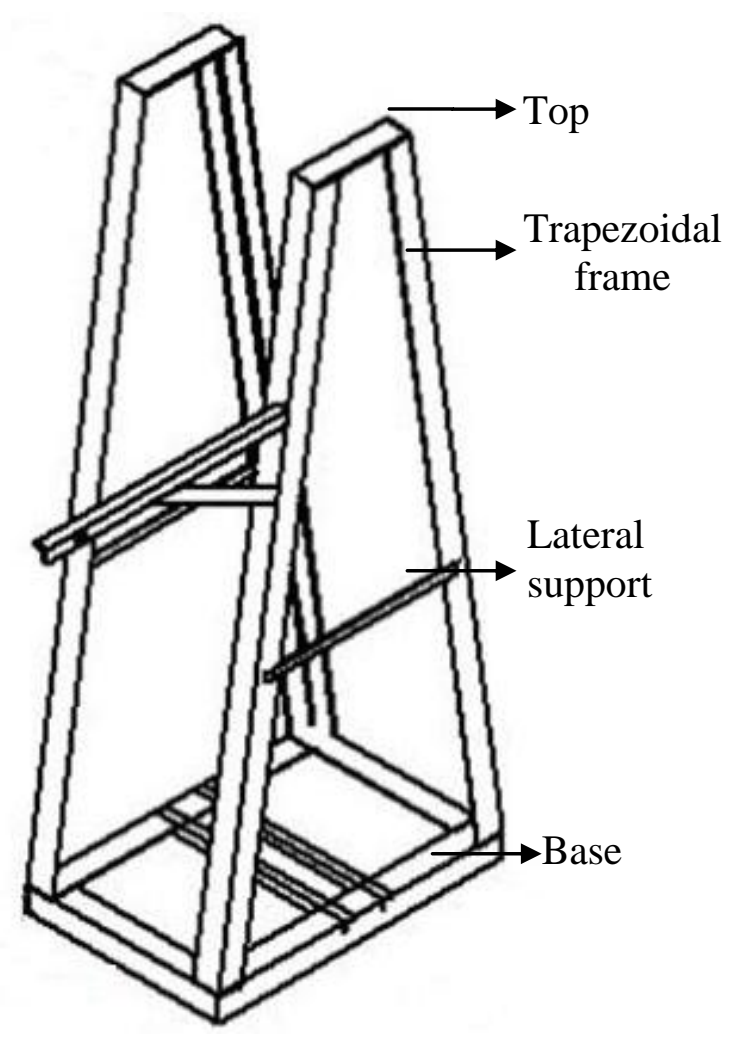

Fig.1 Main frame

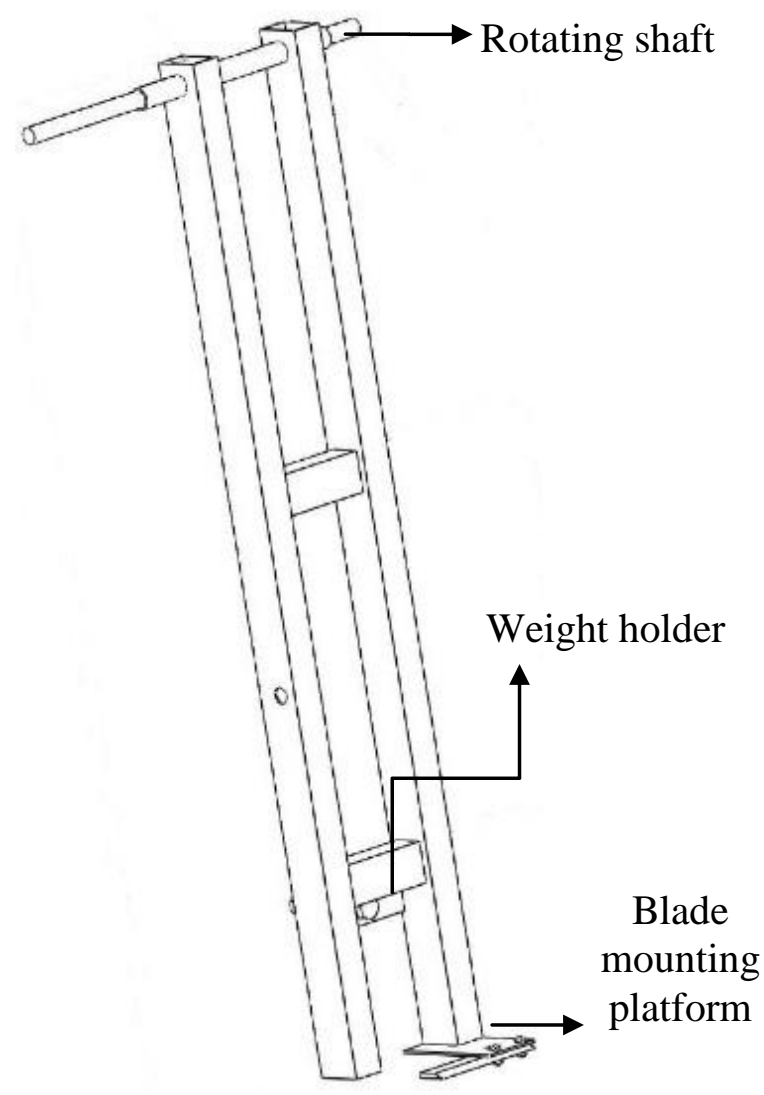

Fig.2 Swing arm

Fig.3 Pendulum type test rig

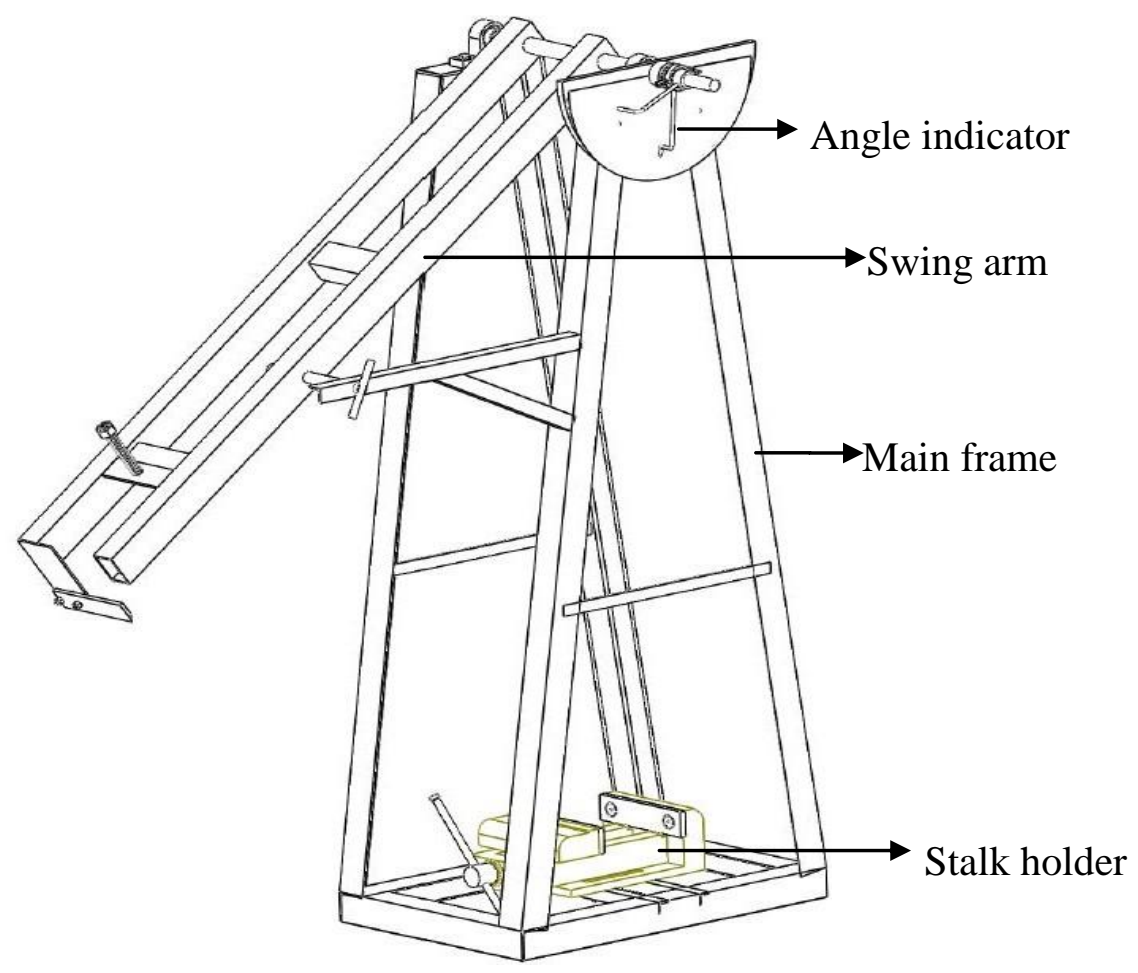


Fig.4 Calibration of pendulum type test rig with different weight on swing arm
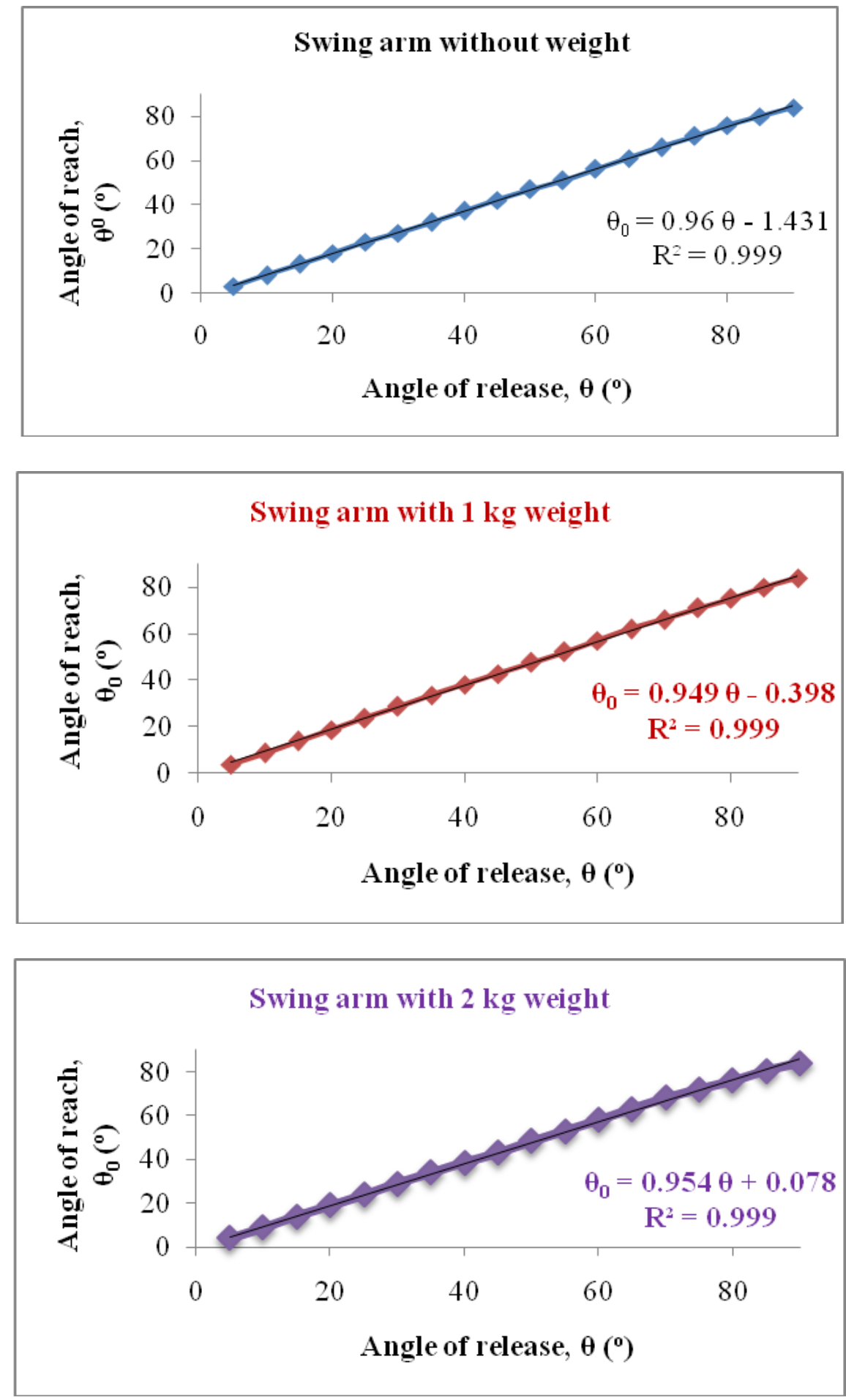

The angle of reach for a pendulum type test rig was calculated by substituting angle of release $(\theta)$ in linear equation.
Swing arm without weight,

$\theta_{0}=0.96 \theta-1.431$ 
Swing arm with $1 \mathrm{~kg}$ weight,

$\theta_{0}=0.949 \theta-0.398$

Swing arm with $2 \mathrm{~kg}$ weight,

$\theta_{0}=0.954 \theta+0.078$

Where,

$\theta_{0}=$ Angle of reach of the swing arm without stem $\left({ }^{\circ}\right)$

$\theta=$ Angle of reach of the swing arm $\left(^{\circ}\right)$

The above equations have many similarities with the equation earned by Yiljep and Mohammad, 2005; Alizadeh et al., 2011 and Azadbakht et al., 2014.

A pendulum type test rig was developed to find the cutting energy of various crop stems. It was calibrated to analyze the cutting energy lose and it was found that a linear relationship between the angle of release and reach with high co-efficient of determination $\left(\mathrm{R}^{2}\right)$ for all the three weights was observed. Three linear equations were obtained to find the angle of reach for the respective weights.

\section{References}

Alizadeh, M.R., F.R. Ajdadi and A. Dabbaghi 2011. Cutting energy of rice stem as influenced by internode position and dimensional characteristics of different varieties. Australian J. Crop Sci., 5(6): 681687.

Azadbakht, M., A.R. Asl and K.T. Zahedi 2014. Energy requirement for cutting corn stalks (Single Cross 704 Var.). International J. Biol. Food Veter. Agrl. Engg., 8(5): 471474.

Dange, A.R., S.K. Thakare, I. Bhaskarrao and U. Momin 2012. Design of front mounted pigeon pea stem cutter. J. Agrl. Tech., 8(2): 417-433.

Hemmatian, R., G. Najari, B. Hosseinzadeh, T.T. Hashjin and M.H. Khoshtaghaza 2012. Experimental and theoretical investigation of the effects of moisture content and internodes position on shearing characteristics of sugarcane stems. J. Agri. Sci. Tech., 14: 963-974.

Hoseinzadeh, B., A. Esehagghbeygi and N. Raghami 2009. Effect of moisture content, bevel angle and cutting speed on shearing energy of three wheat varieties. World Appl. Sci. J., 7(9): 1120-1123.

Koloor, K.R., and G. Kiani 2007. Soybean stems cutting energy and the effect of blade parameters on it. Pakistan J. Biol. Sci., 10(9):1532-1535.

Mahmoodi, E., and A. Jafari, 2010. Influential parameters for designing and power consumption calculating of cumin mower. Australian J. Crop Sci., 4(3):142-149.

McRandal, D.M., and P.B. McNulty 1978. Impact cutting behavior of forage crops - I Mathematical model and laboratory tests. $J$. Agrl. Engg. Res., 23: 816-821.

Prasad, J., and C.P. Gupta 1975. Mechanical properties of maize stalk as related to harvesting. J. Agrl. Engg. Res., 20(1): 7987.

Reza, T.K., 2007. Paddy stems cutting energy and suggested blade optimum parameters. Pakistan J. Biol. Sci., 10(24): 4523-4526.

Visvanathan, R., V.V. Sreenarayanan and K.R. Swaminathan 1996. Effect of knife angle and velocity on the energy required to cut cassava tubers. J. of Agrl. Engg. Res., 64(1): 99-102.

Yilgep, Y., and U. Mohammad 2005. Effect of knife velocity on cutting energy and efficiency during impact cutting of sorghum stalk. CIGR E Journal, 7(1): 1-10.

\section{How to cite this article:}

Prasanthkumar, K. and Saravanakumar, M. 2017. Development and Calibration of Pendulum Type Test Rig. Int.J.Curr.Microbiol.App.Sci. 6(9): 1498-1503. doi: https://doi.org/10.20546/ijcmas.2017.609.182 